\title{
Diagnostic particle agglutination using ultrasound: a new technology to rejuvenate old microbiological methods
}

\author{
RICHARD W. ELLIS and MICHAEL A. SOBANSKI* \\ Department of Medical Microbiology, City Hospital NHS Trust, Birmingham B18 $70 H$ and * School of \\ Biosciences, Cardiff University, PO Box 915, Cardiff CF1 3TL
}

\begin{abstract}
Microbial antigen in clinical specimens can be detected rapidly by commercial test-card latex agglutination, but poor sensitivity is a potential difficulty. Antigen detection by immuno-agglutination of coated latex micro-particles can be enhanced in comparison with the conventional test-card method in both rate and sensitivity by the application of a non-cavitating ultrasonic standing wave. Antibody-coated micro-particles suspended in the acoustic field are subjected to physical forces that promote the formation of agglutinates by increasing particle-particle contact. This report reviews the application of ultrasound to immuno-agglutination testing with several commercial antibody-coated diagnostic micro-particles. This technique is more sensitive than commercial card-based agglutination tests by a factor of up to 500 for fungal cell-wall antigen, 64 for bacterial polysaccharide and 16 for viral antigen (in buffer). The detection sensitivity of meningococcal capsular polysaccharide in patient serum or CSF has been increased to a stage where serotyping by ultrasound-enhanced agglutination is comparable to that achievable with the PCR, but is available more rapidly. Serum antigen concentration as measured by ultrasonic agglutination has prognostic value. Increasing the sensitivity of antigen detection by increasing the acoustic forces that act on suspended particles is considered. Employing turbidimetry to measure agglutination as part of an integrated ultrasonic system would enable the turnover of large numbers of specimens. Ultrasoundenhanced latex agglutination offers a rapid, economical alternative to molecular diagnostic methods and may be useful in situations where microbiological and molecular methods are impracticable.
\end{abstract}

\section{Introduction}

The advent of new nucleic acid technologies, which started with the PCR in the late 1980s, seemed to many to herald the decline of more traditional bacteriological methods, particularly those involved in the rapid detection of micro-organisms and their products [13]. Although not in widespread use at present, PCR and related technologies will play an increasing role in the routine diagnostic laboratory. However, certain areas persist where PCR may not be able to supplant more traditional methods, particularly in the rapid detection of antibody or microbial antigen [2,4].

Immuno-agglutination of latex micro-particles is used in the diagnosis of various infections, and to detect

Received 2 Nov. 1999; revised version accepted 14 March 2000.

Corresponding author: Dr R. W. Ellis. disease markers or chemical compounds in specimens of body fluids [5-8]. Test-card latex particle agglutination (LPA) is usually read by eye as a qualitative indicator in medical diagnostic laboratories [9], although quantitative assays that rely on turbidimetric methods can determine analyte concentration [10]. Standard agglutination methods are perceived in some cases to be insensitive, non-quantitative and difficult to interpret [11-16]. Although nucleic acid detection is more useful diagnostically and clinically than simple immunological detection for some infectious diseases, notably HIV and hepatitis C, in other areas the technical difficulty in discriminating latent infection and reactivation of disease due to the Herpesviridae means that antigen detection can retain a useful role. Indeed, antigen detection and PCR appear to be complementary in some instances [17].

There is the potential to explore existing methods. Increased sensitivity of antigen detection by LPA can 
be achieved by application of a non-cavitating ultrasonic standing wave field. Ultrasound-enhanced particle agglutination can overcome problems associated with standard LPA and may also contribute to good clinical practice in situations where nucleic acid technologies have limitations.

\section{Ultrasonic standing waves}

Standing waves occur when a series of wavefronts travelling through a medium at a fixed frequency and wavelength (the incident waves) meet a series of oppositely directed, identical travelling wavefronts (the coincident waves) [18]. A fixed, constant ultrasonic standing wave system can be generated in one of two ways. The first involves propagation of wavefronts from a piezoelectric transducer (usually planar) [19] through a medium such as water and reflection of the acoustic wave from a suitable reflector $[19,20]$ forming a coincident wavefront which interacts with the incident wave. The reflector may be a water-air interface or a solid surface [19]. The second method is to use a transducer in place of the reflector [18, 21]. This can be achieved by using a tubular transducer (Fig. 1) to form a concentric standing wave field where the highest acoustic pressure is axially focused so that the peak pressure can be up to 10 -fold greater than elsewhere in the field [22].

When particles of the appropriate size, density and compressibility are suspended in a $\mathrm{MHz}$ frequency

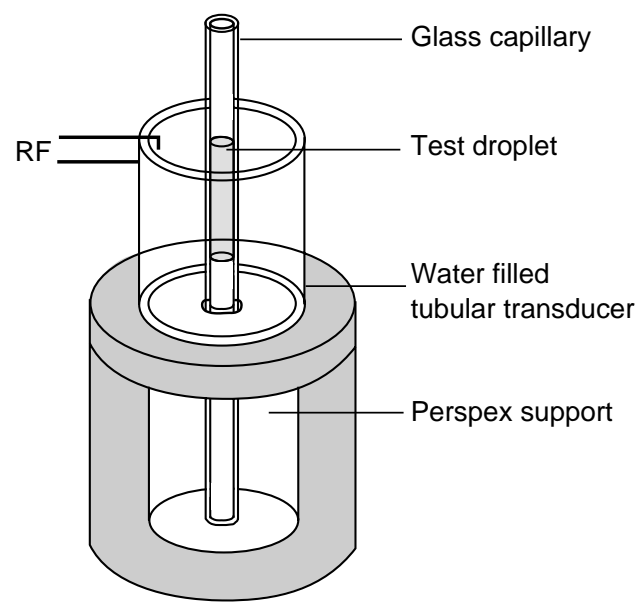

Fig. 1. A view through the ultrasonic chamber showing the tubular transducer (Morgan Matroc, Wrexham) (dimensions: $20 \mathrm{~mm}$ height, $31.5 \mathrm{~mm}$ inside diameter and wall thickness $1.9 \mathrm{~mm}$ ) which was filled with water (for transmission of ultrasound) up to a level c. $1 \mathrm{~mm}$ from the transducer's upper edge. The 50- $\mu 1$ test droplet is held within the $2-\mathrm{mm}$ internal diameter glass capillary (Fisher Scientific, Loughborough) located on the transducer axis by a central hole in the perspex lid (not shown) and perspex support. The transducer was driven at the third harmonic $(4.5 \mathrm{MHz})$ of the fundamental thickness resonance by connecting output from an RF voltage generator to the electroded inner and outer faces of the transducer. ultrasonic standing wave (at a frequency that does not allow disruptive cavitation), several acoustically induced phenomena occur that act to localise the particles at multiple discrete positions throughout the suspending phase $[18,21,23]$. Suspended particles such as antibody-coated microspheres experience an acoustic radiation force $[18,24]$ that causes accumulation of micro-particles at the pressure nodes occurring at half wavelength intervals. Suspended microspheres are also subjected to secondary acoustic attractive forces $[18,24,25]$, which bring the antibody-coated surfaces on distinct particles into even closer proximity [26]. The rate of development of an agglutinate is based on the probability both of close approach and successful cross-link formation between particles in suspension. Close approximation of diagnostic particles in a standing wave field vastly increases the rate of particle collisions needed to enable antigen-antibody cross-linking and enhances the speed and sensitivity of analyte detection in comparison with standard agglutination methods [18]. In the context of the diagnostic microbiology laboratory, ultrasonically increased particle-particle interaction can be accomplished in a rapid controlled manner rather than relying on the lesser effects of Brownian motion, gravity or microvortices produced by circular agitation of reagents on a testcard or glass slide.

\section{Enhancement of diagnostic particle agglutination tests}

Ultrasonic exposure can produce visible agglutination in markedly reduced test times, in the order of minutes rather than the hours over which some of these particle-based tests are performed [22,27] (Table 1). Initial experiments utilised a plane transducer system to generate an ultrasonic standing wave along the axis of a glass capillary tube to agglutinate Legionella cells in the presence of antiserum in $<60 \mathrm{~s}$ rather than the $2 \mathrm{~h}$ conventionally required in microtitration plates [27]. The planar sound field was superseded by use of a radial sound field in which a glass capillary containing the test sample was centrally located on the axis of a tubular transducer (Fig. 1). Reductions in the time required for agglutination reactions in several diagnostic tests - including a reverse passive haemagglutination assay for hepatitis B surface antigen, a conventional Weil-Felix test and a latex agglutination test for anti-cytomegalovirus immunoglobulins [22] were demonstrated (Table 1).

The sensitivity of those tests, which are performed over a series of minutes on a test-card or slide, can be enhanced to a variety of magnitudes by ultrasonic standing wave manipulation. Equal volumes of particle reagent and test specimen are mixed and exposed to ultrasound within a glass capillary (Fig. 1) in the axial high acoustic pressure region of a $4.5 \mathrm{MHz}$ radial acoustic field $[22,28]$. After sonication, the sample is 
Table 1. Diagnostic particle agglutination tests enhanced by standing wave ultrasound

\begin{tabular}{|c|c|c|}
\hline Analyte & Reagent/test used & $\begin{array}{l}\text { Test time } \\
\text { reduction }\end{array}$ \\
\hline $\begin{array}{l}\text { Anti-rickettsial } \\
\text { antibodies [22] }\end{array}$ & Proteus cell agglutination & 48-fold \\
\hline $\begin{array}{l}\text { Anti-cytomegalovirus } \\
\text { antibodies [22] }\end{array}$ & LPA (CMVScan, Becton Dickinson) & 32-fold \\
\hline $\begin{array}{l}\text { Hepatitis B } \\
\text { surface antigen [22] }\end{array}$ & $\begin{array}{l}\text { Reverse passive } \\
\text { haemagglutination turkey } \\
\text { erythrocytes } \\
\text { (Wellcome } \\
\text { Diagnostics) }\end{array}$ & 13-fold \\
\hline $\begin{array}{l}\text { Legionella } \\
\text { pneumophila } \\
\text { serotype } 1 \text { antibodies [27] }\end{array}$ & $\begin{array}{l}\text { L. pneumophila serotype } 1 \\
\text { agglutination }\end{array}$ & 120-fold \\
\hline
\end{tabular}

expelled on to a non-adsorbing surface and stirred manually (two or three rotations with a mixing stick) before microscopic inspection for agglutination $[22,28$, 29]. Increased sensitivity over conventional agglutination testing has been demonstrated for antigen preparations of a particulate (Escherichia coli cells) or soluble nature (C-reactive protein, fungal cell-wall components, bacterial capsular polysaccharide, bacterial protein, viral coat protein) with a radial acoustic field $[28,30-33]$ (Table 2). The sensitivity of fungal antigen detection in buffer (Candida mannan and Aspergillus galactomannan) by ultrasound treatment was also increased in comparison with fungal ELISA
[30]. Such significant increases in sensitivity were made possible by optimal dilution of the latex reagent (so that the particle concentration ensured localised excess antigen levels at nodal regions where particles collect in the sound field), and use of light microscopy for sample examination after sonication (instead of unaided visual observation of latex agglutinates against a 'contrasting' background on a test-card or slide) [28].

There are inherent difficulties arising from increased particle interaction. Ultrasound-induced aggregation as described above has the potential to interfere with test performance; test specificity may be compromised as

Table 2. Increased sensitivity of antigen detection by standing wave ultrasound compared to conventional particle agglutination

\begin{tabular}{|c|c|c|c|}
\hline Analyte & Reagent used & $\begin{array}{c}\text { Sensitivity } \\
\text { enhancement }\end{array}$ & $\begin{array}{l}\text { Agglutinate } \\
\text { detection }\end{array}$ \\
\hline \multicolumn{4}{|l|}{$\begin{array}{l}\text { Fungal cell wall } \\
\text { components [30] }\end{array}$} \\
\hline $\begin{array}{l}\text { Aspergillus fumigatus } \\
\text { galactomannan }\end{array}$ & $\begin{array}{l}\text { LPA (Pastorex, } \\
\text { Sanofi Diagnostics) }\end{array}$ & $\times 500$ & Videomicroscopy \\
\hline Candida albicans mannan & & $\times 250$ & \\
\hline \multicolumn{4}{|l|}{ Soluble protein $[28]$} \\
\hline C-reactive protein & $\begin{array}{l}\text { LPA (Mercia } \\
\text { Diagnostics, Centocor) }\end{array}$ & $\begin{array}{l}\times 256 \\
\times 2560\end{array}$ & $\begin{array}{l}\text { Videomicroscopy } \\
\text { Image analysis }\end{array}$ \\
\hline \multicolumn{4}{|l|}{$\begin{array}{l}\text { Soluble capsular } \\
\text { polysaccharide [32] }\end{array}$} \\
\hline $\begin{array}{l}\text { N. meningitidis group } \\
\mathrm{A}, \mathrm{C}, \mathrm{Y}, \mathrm{W} 135\end{array}$ & LPA (Wellcogen, Murex Diagnostics) & $\times 64$ & $\begin{array}{l}\text { Microscopy or image } \\
\text { analysis }\end{array}$ \\
\hline$N$. meningitidis group $\mathrm{B} / E$. coli $\mathrm{K} 1$ & & $\times 32$ & \\
\hline Streptococcus pneumoniae & & $\times 16$ & \\
\hline Streptococcus group B & & $\times 16$ & \\
\hline Haemophilus influenzae & & $\times 32$ & \\
\hline Meningococcal antigen & $\begin{array}{l}\text { Staphylococcal } \\
\text { co-agglutination } \\
\text { (Phadebact) }\end{array}$ & $\times 64$ & \\
\hline \multicolumn{4}{|l|}{$\begin{array}{l}\text { Inactivated bacterial } \\
\text { cells }[28,31]\end{array}$} \\
\hline $\begin{array}{l}\text { E. coli } \mathrm{O} 157 \text { (somatic } \\
\text { antigen) }\end{array}$ & LPA (Unipath) & $\times 1024$ & Videomicroscopy \\
\hline $\begin{array}{l}\text { E. coli serotype } \mathrm{O} 18: \mathrm{KU} \\
\text { (common pilus positive) }\end{array}$ & In-house LPA & $\times 10000$ & Microscopy \\
\hline E. coli $\mathrm{O} 75: \mathrm{K} 1$ & $\begin{array}{l}\text { LPA (Wellcogen, } \\
\text { Murex Diagnostics) }\end{array}$ & $\times 2048$ & \\
\hline \multicolumn{4}{|l|}{ Viral antigen $[33]$} \\
\hline Rotavirus outer coat antigen & $\begin{array}{l}\text { LPA (Slidex rotakit, } \\
\text { bioMérieux) }\end{array}$ & $\times 16$ & Turbidimetry \\
\hline
\end{tabular}

${ }^{*}$ Defined as the increase in dilution of antigen giving positive agglutination. 
the monodispersity of the latex suspension decreases following sonication. Therefore, the procedure has been developed so as to incorporate a physical step (manual stirring being the simplest approach) whereby shearing forces are introduced to eliminate non-specific aggregation, leaving agglutinates that are specifically bridged by antibody-antigen interaction relatively intact. Although weakly bound non-specific clumps dissociate to form discrete particles, some background residual aggregation persists [29] which may influence operator judgment, particularly in borderline cases at the threshold level of antigen needed for stable crosslinking. However, subjectivity can be overcome through operator experience [29], the use of videomicroscope image analysis techniques [32] or turbidimetric methods [33] and all ultrasonic tests examined to date have retained sensitivity and specificity in clinical testing $[34,35]$. Uniform shearing forces have been applied to sonicated samples with a plane and cone viscometer [26], but such a process may limit the suitability of the technique for rapid investigation in routine laboratory diagnosis. Allowance for the degree of non-specific clumping is accomplished in conjunction with photometric methods such as turbidimetry or nephelometry, where the degree of ultrasonically induced aggregation in the absence of the target moiety can be measured and compared to the photometric properties of the nonsonicated particle suspension [33].

The transition from the detection of microbial antigen in non-clinical preparations to the screening of various body fluids (serum, plasma, urine or CSF) requires specimen processing to remove particulate matter and to eliminate cross-reactive material that can induce non-specific agglutination [36, 37]. Heat denaturation and clarification by filtration can remove soluble protein [38] that could potentially compromise test specificity.

Ultrasound-enhanced antigen detection in clinical specimens has been most extensively studied for the capsular polysaccharides produced by the bacteria that cause meningitis and septicaemia [29, 32, 34, 35, 39]. Non-culture case confirmation of disease is important, as immediate antibiotic administration is recommended if bacterial meningitis is suspected clinically [40, 41].
In the UK, information from PCR may be subject to delay, as specimens are usually dispatched to an accredited reference laboratory for analysis [40]. Rapid detection of polysaccharide antigen and hence prompt notification of disease is possible locally by conventional LPA [14], but the sensitivity can be increased up to 64 -fold by using ultrasound $[32,34]$. Recent studies have shown that ultrasound-enhanced agglutination approaches the sensitivity of PCR-based assays [35, $40,42]$ currently in use, for confirming the presence of meningococci (Table 3). A five-fold increase was found in the number of meningococcal cases identified by ultrasound in comparison with conventional LPA [35], raising the possibility of using ultrasonic enhancement for routine blood testing. Serogrouping of Neisseria meningitidis from blood or CSF specimens was complementary with PCR [42] and ultrasonic agglutination, with some samples being grouped by ultrasound but not PCR and vice versa [35]. Futhermore, the serum antigen concentration (as determined ultrasonically by titration of antigen-positive specimens) correlates with prognosis [43], making new information available that may have a direct influence on patient management.

Non-specific agglutination because of immunological similarities between unrelated microbial epitopes or non specific protein-protein interaction has been documented for conventional LPA [44, 45] and in some cases has been exploited [46]. It has been shown that the occurrence of non-specific agglutination resulting from immunological cross-reactivity does not increase as a consequence of greater particle interaction in an ultrasonic standing wave $[32,34]$.

\section{The future of ultrasound-enhanced particle agglutination}

\section{Clinical application}

Ultrasonic enhancement of particle agglutination may find a diagnostic niche as a rapid analytical method. Preliminary results obtained as part of a multicentre evaluation of the technique suggest that case confirmation and grouping of $N$. meningitidis in CSF and blood can actually be improved by using ultrasonically

Table 3. Sensitivities of detection of $N$. meningitidis in patients (percentage of patients where meningococci were identified) with clinically confirmed meningococcal disease $(n=90)$ and for a subset of patients $(n=26)$ with microbiologically confirmed meningococcal disease [35]

\begin{tabular}{lcc}
\hline Test & $\begin{array}{c}\text { Sensitivity in } \\
\text { clinically diagnosed } \\
\text { cases (\%) }\end{array}$ & $\begin{array}{c}\text { Sensitivity in } \\
\text { microbiologically } \\
\text { diagnosed cases (\%) }\end{array}$ \\
\hline Conventional LPA (Wellcogen, & 10 & 19 \\
Murex Diagnostics) & 50 & 76 \\
Ultrasonic immunoassay & 67 & 88 \\
Meningococcal screening PCR assay [40] & 48 & 69 \\
Meningococcal serogrouping PCR assay [42] & 28 & 100 \\
Culture & & \\
\hline
\end{tabular}


enhanced latex agglutination alongside PCR [35]. The improvements demonstrated to date indicate that most benefit could be derived in areas where present laboratory methods are lacking, for instance in the diagnosis of disseminated fungal disease [30], an area where ultrasound has already demonstrated its potential. Standard LPA has been shown to be inferior to both PCR and ELISA in detection of Aspergillus [47], but PCR assays currently in development do not appear to offer significant advantages in sensitivity over antigen detection [48]. In living patients, the inability of PCR to diagnose some infectious diseases retrospectively, compared with the ability of antibody detection, is yet another potential area where this new technology can be explored. Existing evidence points to a powerful new technology which offers an economic alternative to molecular diagnostic methods. Commercial LPA reagents are relatively inexpensive and the one-off cost of an integrated ultrasonic device - the only prototype of which has been used by both authors - has been estimated as $<\$ 4000$ [35]. Also, ultrasonic agglutination remains a basic technique and so may be suited to disease surveillance in developing countries where routine culture and PCR are often impracticable and where specialist laboratories and staff may not be available.

\section{Potential for further sensitivity enhancements}

Ultrasound-enhanced agglutination assays currently employ commercial latex reagents that are optimised for the test-card format. The volume, density and compressibility of particles relative to the suspending phase modifies the ultrasonic radiation and interaction forces that the particles experience and hence particles of a larger volume or greater density are more suited for acoustic manipulation [21, 24]. Increased ultrasonic assay sensitivity has been shown with larger polystyrene microspheres in contrast to small particles of the same material [31] and with microspheres of a greater density such as silica than with equal sized latex particles (Table 4) [26]. Improved analyte detection is correlated with the greater acoustic inter-particle attractive forces (bringing surface-bound molecules into closer proximity than with submicron latex) as a result of increased size, density and reduced compressibility [26].

Although silica microspheres have been used as solid supports for immobilised protein in particle agglutination tests [49], the commercial availability of silicabased assays is limited at present because of factors relating to density such as colloidal stability and low refractive index, which makes agglutinates harder to visualise in the test-card format [50]. Silica-based tests are attractive because the hydrophilic particle surface reduces non-specific hydrophobic interaction [50]. Continuing improvements in particle-surface chemistry, e.g., attachment of antibody via spacer molecules [5153], may make silica the optimal particle of choice for high throughput ultrasonic screening assays and the detection of low levels of analyte [26].

\section{Potential for automated multiple sample analysis}

Automation allows large sample numbers to be screened. Image analysis of agglutinate size improved the antigen detection threshold previously found for Creactive protein a further 10-fold [54] and enabled quantitative measurement of analyte concentration (Table 2). The ultrasonic process, like many other nascent technologies, is extremely amenable to automation and it is possible to envisage an entirely selfcontained flow-through system [22] using photometric analysis to enable rapid specimen turnover. Photometric methods are easily incorporated into on-line systems $[55,56]$ and turbidimetry has been used in the ultrasonic detection of purified rotavirus outer coat antigen with commercial LPA reagents [33].

\section{Other applications of ultrasound in analytical methods and biotechnology}

The bringing of small particles together has many potential applications within biomedical science. In the brewing and pharmaceutical industries, standing wave technology can be used as a form of particle separator where the once useful but now undesirable microorganisms can be separated from their products [57] in batch [58] or flow systems [59]. The electro-fusion of murine hybridoma cells can be accomplished within an

Table 4. Sensitivity enhancements for biotinylated bovine serum albumin (BSA) and rabbit immunoglobulin for similar sized coated silica or latex particles with ultrasound treatment in comparison to conventional LPA [26]

\begin{tabular}{llcc}
\hline Analyte & Coated particle & $\begin{array}{c}\text { Sensitivity } \\
\text { enhancement }\end{array}$ & $\begin{array}{c}\text { Improvement } \\
\text { with silica }\end{array}$ \\
\hline Biotinylated & Streptavidin-coated & & \\
BSA & $0.3 \mu$ silica & $\times 125$ & $\times 12$ \\
& $0.25 \mu$ latex & $\times 10$ & \\
Rabbit anti- & Mouse IgG-coated & & \\
mouse IgG & $1.0 \mu$ silica & $\times 80$ & \\
& $1.0 \mu$ latex & $\times 12$ & \\
\hline
\end{tabular}


ultrasonic standing wave field and may be useful in the production of monoclonal antibodies [60]. Examples of ultrasonic clarification of mammalian cell suspensions include industrial use of an ultrasonic filter to retain cells in an acoustic field allowing downstream purification of antibody from the fermentation filtrate [61].

Disruptive cavitating ultrasound has been used to enhance the sensitivity of an enzyme immunoassay by disturbing the stable solvent barrier above antibody immobilised on a solid phase, thus increasing molecular diffusion across the liquid-solid surface interface and accelerating antigen-antibody binding kinetics [62]. It is also noteworthy that increased particleparticle interaction can be achieved by applying an alternating-current electric field, thereby enhancing both the rate of latex particle agglutination and the sensitivity of antigen detection [63].

\section{Conclusions}

More and more diagnostic particle agglutination tests are already being examined by the ultrasonic technique as confidence in the technology grows and similar enhancements are being seen across both antigen and antibody detection tests. The potential exists to explore generic analytical uses for ultrasonic immuno-particle agglutination in both clinical and biotechnological areas (e.g. contamination screening [64]). Expanding the clinical usefulness of the ultrasonic technique precedes application in areas where molecular methods are not possible, such as screening for chemical compounds in patient body fluids. Such developments in routine use could bring new life to ageing techniques.

M.A.S. was supported by the Meningitis Research Foundation (UK) The authors are grateful to Dr R. A. Barnes (University of Wales College of Medicine) for helpful discussions on the manuscript.

\section{References}

1. Carrino JJ, Lee HH. Nucleic acid amplification methods. $J$ Microbiol Methods 1995; 23: 3-20.

2. Karch H, Schwarzkopf A, Schmidt H. Amplification methods in diagnostic bacteriology (selected examples). $J$ Microbiol Methods 1995; 23: 55-73.

3. Swaminathan B, Barrett, TJ. Amplification methods for epidemiologic investigations of infectious diseases. J Microbiol Methods 1995; 23: 129-139.

4. Altwegg M. General problems with diagnostic applications of amplification methods. J Microbiol Methods 1995; 23: 21-30.

5. Kaldor J, Asznowicz R, Buist DGP. Latex agglutination in diagnosis of bacterial infections, with special reference to patients with meningitis and septicemia. Am J Clin Pathol 1977; 68: 284-289.

6. Büscher P, Lejon V, Magnus E, Van Meirvenne N. Improved latex agglutination test for detection of antibodies in serum and cerebrospinal fluid of Trypanosoma brucei gambiense infected patients. Acta Tropica 1999; 73: 11-20.

7. García A, Rosón B, Pérez JL et al. Usefulness of PCR and antigen latex agglutination test with samples obtained by transthoracic needle aspiration for diagnosis of pneumococcal pneumonia. J Clin Microbiol 1999; 37: 709-714.

8. D'Hallewin M-A, Baert L. Initial evaluation of the bladder tumor antigen test in superficial bladder cancer. J Urol 1996; 155: $475-476$

9. Leinonen M, Herva E. The latex agglutination test for the diagnosis of meningococcal and Haemophilus influenzae meningitis. Scand J Infect Dis 1977; 9: 187-191.

10. Newman DJ, Henneberry H, Price CP. Particle enhanced light scattering immunoassay. Ann Clin Biochem 1992; 29: 22-42.

11. Mein J, Lum G. CSF bacterial antigen detection tests offer no advantage over Gram's stain in the diagnosis of bacterial meningitis. Pathology 1999; 31: 67-69.

12. Narchi H. Bacterial antigen detection testing in the diagnosis of meningitis. Ann Saudi Med 1997; 17:101-103.

13. Perkins MD, Mirrett S, Reller LB. Rapid bacterial antigen detection is not clinically useful. J Clin Microbiol 1995; 33: 1486-1491.

14. Finlay FO, Witherow H, Rudd PT. Latex agglutination testing in bacterial meningitis. Arch Dis Child 1995; 73: 160-161.

15. Harrison LH, Steinhoff MC, Sridharan G et al. Monovalent latex agglutination reagents for the diagnosis of nonmeningitic pneumococcal infection. Diagn Microbiol Infect Dis 1996; 24: $1-6$.

16. Sanchez ML, Pfaller MA, Cabezudo I, Bale M, Buschelman B. Diagnosis of disseminated candidiasis in hospitalized patients using the Cand-Tec latex agglutination assay. Mycopathologia 1992; 118: 153-162.

17. al-Wali W, Hughes C. Urine antigen detection can be quicker than PCR in the diagnosis of meningococcal disease. J Hosp Infect 1998; 40: 326-328.

18. Coakley WT. Ultrasonic separations in analytical biotechnology. Trends Biotechnol 1997; 15: 506-511.

19. Zamani AF, Owen RW, Clarke DJ. Ultrasonic standing waves: microbiological applications. In: Kroll RG, Gilmour A, Sussman $M$ (eds) New techniques in food and beverage microbiology. (Society for Applied Bacteriology) Technical series no. 31. Oxford, Blackwell Scientific Publications. 1993: 55-66.

20. Woodside SM, Piret JM, Gröschl M, Benes E, Bowen BD. Acoustic force distribution in resonators for ultrasonic particle separation. AIChE J 1998; 44: 1976-1984.

21. Coakley WT, Whitworth G, Grundy MA, Gould RK, Allman R. Ultrasonic manipulation of particles and cells. Bioseparation 1994; 4: 73-83.

22. Grundy MA, Bolek WE, Coakley WT, Benes E. Rapid agglutination testing in an ultrasonic standing wave. $J$ Immunol Methods 1993; 165: 47-57.

23. Whitworth G, Grundy MA, Coakley WT. Transport and harvesting of suspended particles using modulated ultrasound. Ultrasonics 1991; 29: 439-444.

24. Coakley WT, Bardsley DW, Grundy MA, Zamani F, Clarke DJ. Cell manipulation in ultrasonic standing wave fields. $J$ Chem Technol Biotechnol 1989; 44: 43-62.

25. Weiser MAH, Apfel RE, Neppiras EA. Interparticle forces on red cells in a standing wave field. Acustica 1984; 56: 114-119.

26. Thomas NE, Sobanski MA, Coakley WT. Ultrasonic enhancement of coated particle agglutination immunoassays: influence of particle density and compressibility. Ultrasound Med Biol 1999; 25: 443-450.

27. Jepras RI, Clarke DJ, Coakley WT. Agglutination of Legionella pneumophila by antiserum is accelerated in an ultrasonic standing wave. J Immunol Methods 1989; 120: 201-205.

28. Grundy MA, Moore K, Coakley WT. Increased sensitivity of diagnostic latex agglutination tests in an ultrasonic standing wave field. J Immunol Methods 1994; 176: 169-177.

29. Sobanski MA, Gray SJ, Cafferkey M, Ellis RW, Barnes RA, Coakley WT. Meningitis antigen detection: interpretation of agglutination by ultrasound-enhanced latex immunoassay. $\mathrm{Br} J$ Biomed Sci 1999; 56: 239-246.

30 Grundy MA, Barnes RA, Coakley WT. Highly sensitive detection of fungal antigens by ultrasound-enhanced latex agglutination. J Med Vet Mycol 1995; 33: 201-203.

31. Gualano MP, Grundy MA, Coakley WT, Parry SH, Stickler DJ. Ultrasound-enhanced latex agglutination for the detection of bacterial antigens in urine. Br J Biomed Sci 1995; 52:178183.

32. Jenkins P, Barnes RA, Coakley WT. Detection of meningitis antigens in buffer and body fluids by ultrasound-enhanced particle agglutination. J Immunol Methods 1997; 205: 191200. 
33. Ellis RW, Hastings JGM, Sobanski MA. Enhancement of rotavirus latex detection by ultrasonic standing wave treatment (abstract). J Infect 1998; 36: A12.

34. Barnes RA, Jenkins P, Coakley WT. Preliminary clinical evaluation of meningococcal disease and bacterial meningitis by ultrasonic enhancement. Arch Dis Child 1998; 78: 58-60.

35. Gray SJ, Sobanski MA, Kaczmarski EB et al. Ultrasoundenhanced latex immunoagglutination and PCR as complementary methods for non-culture-based confirmation of meningococcal disease. J Clin Microbiol 1999; 37:1797-1801.

36. Doskeland SO, Berdal BP. Bacterial antigen detection in body fluids: methods for rapid antigen concentration and reduction of nonspecific reactions. J Clin Microbiol 1980; 11: 380-384.

37. Gooch WM. Immunologic diagnosis of infectious disease by antigen detection in urine. $J$ Med Technol 1985; 2: 762-765.

38. Weinberg GA, Storch GA. Preparation of urine samples for use in commercial latex agglutination tests for bacterial antigens. $J$ Clin Microbiol 1985; 21: 899-901.

39. Gray SJ, Guiver M, Sobanski MA et al. Diagnosis of meningococcal disease: a comparison of ultrasonic-enhanced latex agglutination with PCR. In: Abstracts of the 38th Interscience Conference on Antimicrobial Agents and Chemotherapy, San Diego. Washington, DC, American Society for Microbiology. 1998: D-22, 133.

40. Kaczmarski EB, Ragunathan PL, Marsh J, Gray SJ, Guiver M. Creating a national service for the diagnosis of meningococcal disease by polymerase chain reaction. Commun Dis Public Health 1998; 1: 54-56.

41. Booy R, Kroll JS. Bacterial meningitis and meningococcal infection. Curr Opin Pediatr 1998; 10: 13-18.

42. Borrow R, Claus $\mathrm{H}$, Guiver $\mathrm{M}$ et al. Non-culture diagnosis and serogroup determination of meningococcal $\mathrm{B}$ and $\mathrm{C}$ infection by a sialyltransferase (siaD) PCR ELISA. Epidemiol Infect 1997; 118: $111-117$.

43. Sobanski MA, Barnes RA, Gray SJ et al. Measurement of serum antigen concentration by ultrasound enhanced immunoassay and correlation with clinical outcome in meningococcal disease. Eur J Clin Microbiol (in press).

44. Ajello GW, Bolan GA, Hayes PS et al. Commercial latex agglutination tests for detection of Haemophilus influenzae type $\mathrm{b}$ and Streptococcus pneumoniae antigens in patients with bacteremic pneumonia. J Clin Microbiol 1987; 25: 1388-1391.

45. Robbins JB, Myerowitz RL, Whisnant JK et al. Enteric bacteria cross-reactive with Neisseria meningitidis groups A and $\mathrm{C}$ and Diplococcus pneumoniae types I and III. Infect Immun 1972; 6: 651-656.

46. Fallon RJ, McIllmurray MB. Escherichia coli K1. Lancet 1976; 1: 201.

47. Kawamura S, Maesaki S, Noda $\mathrm{T}$ et al. Comparison between PCR and detection of antigen in sera for diagnosis of pulmonary aspergillosis. J Clin Microbiol 1999; 37: 218-220.

48. Van Burik J-A, Myerson D, Schreckhise RW, Bowden RA. Panfungal PCR assay for detection of fungal infection in human blood specimens. J Clin Microbiol 1998; 36: 1169 1175 .

49. Yoshinaga K, Kondo A, Higashitani K, Kito T. Immobilization of protein on monodispersed colloidal silica with poly(ethylene glycol) spacer and application of the composites to immunological agglutination tests. Colloid Surface A 1993; 77: 101107.

50. Bangs L. Diagnostic applications of latex technology: The latex course. Bangs Laboratories Inc., Emerald Diagnostics Inc. and Prolabo. 1996, Paris.

51. Yoshinaga K, Kondo K, Kondo A. Efficient immobilization of protein on monodispersed colloidal silica particles modified by copolymers of maleic anhydride and styrene or methyl methacrylate. Polym J 1995; 27: 98-100.

52. Yoshinaga K, Kondo K, Kondo A. Capabilities of polymermodified monodisperse colloidal silica particles as biomaterial carrier. Colloid Polym Sci 1997; 275: 220-226.

53. Lu B, Xie J, Lu C, Wu C, Wei Y. Oriented immobilization of Fab fragments on silica surfaces. Anal Chem 1995; 67: 83-87.

54. Thomas NE, Coakley WT. Measurement of antigen concentration by an ultrasound-enhanced latex immunoagglutination assay. Ultrasound Med Biol 1996; 22: 1277-1284.

55. Hawkes JJ, Barrow D, Cefai J, Coakley WT. A laminar flow expansion chamber facilitating downstream manipulation of particles concentrated using an ultrasonic standing wave. Ultrasonics 1998; 36: 901-903.

56. Hawkes JJ, Barrow D, Coakley WT. Microparticle manipulation in millimetre scale ultrasonic standing wave chambers. Ultrasonics 1998; 36: 925-931.

57. Miles CA, Morley MJ, Hudson WR, Mackey BM. Principles of separating micro-organisms from suspensions using ultrasound. J Appl Bacteriol 1995; 78: 47-54.

58. Limaye MS, Hawkes JJ, Coakley WT. Ultrasonic standing wave removal of microorganisms from suspension in small batch systems. J Microbiol Methods 1996; 27: 211-220.

59. Hawkes JJ, Coakley WT. A continuous flow ultrasonic cellfiltering method. Enzyme Microb Technol 1996; 19: 57-62.

60. Bardsley DW, Liddell JE, Coakley WT, Clarke DJ. Electroacoustic production of murine hybridomas. J Immunol Methods 1990; 129: 41-47.

61. Trampler F, Sonderhoff SA, Pui PWS, Kilburn DG, Piret JM. Acoustic cell filter for high density perfusion culture of hybridoma cells. Biotechnology 1994; 12: 281-284.

62. Chen R, Weng L, Sizto NC et al. Ultrasound-accelerated immunoassay, as exemplified by enzyme immunoassay of choriogonadotropin. Clin Chem 1984; 30: 1446-1451.

63. Song MI, Iwata K, Yamada M et al. Multisample analysis using an array of microreactors for an alternating-current fieldenhanced latex immunoassay. Anal Chem 1994; 66: 778-781.

64. Matar GM, Hayes PS, Bibb WF, Swaminathan B. Listeriolysin O-based latex agglutination test for the rapid detection of Listeria monocytogenes in foods. J Food Protect 1997; 60: $1038-1040$. 